Tecnología y

Ciencias $\stackrel{\Xi}{\unlhd}$ Aua
2020, Instituto Mexicano de Tecnología del Agua

Open Access bajo la licencia CC BY-NC-SA 4.0

(https://creativecommons.org/licenses/by-nc-sa/4.0/)

DOI: $10.24850 /$ j-tyca-2020-03-09

Artículos

\title{
Remoción bacteriana de cinc y cadmio: estudio de factores asociados con el proceso
}

\section{Zinc and cadmium removal by bacteria: Study of factors associated to the process}

Lizandra Pérez ${ }^{1}$, ORCID: https://orcid.org/0000-0002-8597-7456

Armando Martínez ${ }^{2}$

Irina Salgado3, ORCID: https://orcid.org/0000-0002-7175-8500

Luis Alberto Valdés ${ }^{4}$, ORCID: https://orcid.org/0000-0003-1587-2234

Mario $\mathrm{Cruz}^{5}$

Sheila Allende 6

Odalys Collazo ${ }^{7}$

María Liva 8

María Elena Carballo9 ${ }^{9}$ ORCID: https://orcid.org/0000-0003-2671-9323

${ }^{1}$ Facultad de Biología, Universidad de La Habana, La Habana, Cuba, lizandra@fbio.uh.cu

2Facultad de Biología, Universidad de La Habana, La Habana, Cuba, armando@fbio.uh.cu 
${ }^{3}$ Facultad de Biología, Universidad de La Habana, La Habana, Cuba, irina@fbio.uh.cu

4Glendale Community College, Glendale, EUA, lui2152145@maricopa.edu ${ }^{5}$ Facultad de Biología, Universidad de La Habana, La Habana, Cuba, mcruz@fbio.uh.cu

${ }^{6}$ Instituto de Tecnología y Ciencia de Materiales, Universidad de La Habana, La Habana, Cuba, salleyne@imre.uh.cu

${ }^{7}$ Instituto de Tecnología y Ciencia de Materiales, Universidad de La Habana, La Habana, Cuba, ody@imre.uh.cu

${ }^{8}$ Instituto de Tecnología y Ciencia de Materiales, Universidad de La Habana, La Habana, Cuba, liva@imre.uh.cu

${ }^{9}$ Facultad de Biología, Universidad de La Habana, mecarballo@fbio.uh.cu

Autora para correspondencia: María Elena Carballo, mecarballo@fbio.uh.cu

\section{Resumen}

Las capacidades de los microorganismos de captar metales presentes en ecosistemas acuáticos constituyen una alternativa para la conservación ambiental y de los recursos naturales. En el presente trabajo se evaluó la capacidad de biosorción de cinc y cadmio en soluciones acuosas por cepas de las especies bacterianas Proteus mirabilis y Bacillus subtilis, así como la influencia de diferentes variables, como la edad fisiológica del cultivo, la concentración celular, el pH, el tiempo de contacto y el pretratamiento 
con métodos físicos y químicos de la biomasa celular en el proceso de remoción. En los estadios fisiológicos evaluados no se observó diferencia en la captura de los metales por los cultivos bacterianos y 2 g. $\mathrm{L}^{-1}$ de biomasa fueron suficientes para alcanzar altos valores de captura. Se determinó que la mayor influencia en el proceso la ejerce el pH empleado, el tiempo de contacto y el efecto de cada tratamiento a la biomasa bacteriana. Los resultados muestran la efectividad de las biomasas microbianas investigadas en la biosorción de cinc y cadmio, y sus potencialidades para el saneamiento ambiental.

Palabras clave: biosorción, biomasas microbianas, cinc, cadmio, factores bióticos y abióticos.

\section{Abstract}

Metallic ions in aquatic ecosystems are considered important inorganic pollutants of the environment due to their mobility and toxicity to living organisms. The capacities of microorganisms to capture the metals present in aquatic ecosystems constitute an alternative for the conservation of natural resources. In the present work we evaluated the biosorption capacities of zinc and cadmium by bacterial strains of Proteus mirabilis and Bacillus subtilis in aqueous solutions, as well as the influence of different variables such as culture physiological age, cell concentration, $\mathrm{pH}$, contact time and pre-treatment of cell biomass with physical and chemical methods. The capture of metals by bacterial cultures did not present differences in the different physiological stages evaluated and 2 g. $\mathrm{L}^{-1}$ of biomass were enough to reach high capture values. It was determined that the greatest influence in the process lies in the $\mathrm{pH}$ used, 
the contact time and the effect of each treatment to bacterial biomass. The results show the effectiveness of tested microbial biomasses in the biosorption of zinc and cadmium and their potential for environmental sanitation.

Keywords: Biosorption, microbial biomasses, zinc, cadmium, biotic and abiotic factors.

Recibido: 26/07/2017

Aceptado: 10/09/2019

\section{Introducción}

La contaminación del ambiente surge en gran medida como resultado de actividades humanas, principalmente industriales y agrícolas (BeltránPineda \& Gómez-Rodríguez, 2016), que ocasionan vertimientos de aguas residuales con insuficiente tratamiento para eliminar su carga de contaminantes (Chowdhury, Jafar, Al-Atta, \& Husain, 2016). Estos son descargados a los ecosistemas donde pueden alcanzar concentraciones elevadas, especialmente cerca del sitio de descarga, lo que provoca el deterioro del entorno (Nour-Abdel-Ghani \& Ghadir-El-Chaghaby, 2014). Entre los principales contaminantes se encuentran los metales pesados, 
que a diferencia de los contaminantes químicos de origen orgánico no se degradan por vía biológica ni química, y persisten largos periodos de tiempo en ambientes acuáticos y terrestres (Salgado-Bernal, Pérez, Carballo, Martínez, \& Cruz, 2015). La acumulación de los iones metálicos en los organismos de los diferentes eslabones de la cadena trófica (Mehta \& Kumar, 2017), su movilidad en los ecosistemas y su toxicidad hacen que su eliminación constituya una prioridad en el mundo (Nour-AbdelGhani \& Ghadir-El-Chaghaby, 2014).

Los metales pesados son imprescindibles para el desarrollo de microorganismos, plantas y animales, pues ejercen roles importantes en algunas reacciones bioquímicas y son esenciales para su crecimiento y desarrollo. Sin embargo, cuando se presentan en altas concentraciones pueden formar compuestos inespecíficos con efectos citotóxicos y letales. Si bien algunos metales tienen importancia biológica, otros son tóxicos, como el cadmio, cromo y mercurio (Beltrán-Pineda \& Gómez-Rodríguez, 2016). En este sentido, el cinc no es altamente tóxico, por considerarse un elemento esencial para la vida, pero se han encontrado efectos adversos en concentraciones elevadas (Kvasnová, Hamarováb, \& Pristašc, 2017), entre 100 y 500 mg/día (Volesky, 1994). Por otro lado, la toxicidad del cadmio es ampliamente conocida por la destrucción de sitios enzimáticos activos (Essa, Al-Abboud, \& Khatib, 2017) y alteraciones del sistema nervioso en seres humanos, incluso a bajas concentraciones (Chauhan, Solanki, \& Nehra, 2017), hasta 10 mg/día (Kjellstrom \& Nordberg, 1985).

Con el propósito de asegurar la protección e integridad de los recursos hídricos contaminados con metales pesados, las restricciones al vertimiento de las aguas contaminadas resultan cada vez más estrictas 
Tecnología y

Ciencias $\stackrel{\unlhd}{\unlhd}$ gua
2020, Instituto Mexicano de Tecnología del Agua

Open Access bajola licencia CC BY-NC-SA 4.0

(https://creativecommons.org/licenses/by-nc-sa/4.0/)

(Nour-Abdel-Ghani \& Ghadir-El-Chaghaby, 2014). Además, se intensifican las investigaciones ambientales que aprovechan la diversidad microbiana, y sus potencialidades estructurales y metabólicas como agentes biorremediadores para el tratamiento de aguas residuales, y en la restauración de ambientes contaminados (Irawati, Riak, Sopiah, \& Sulistia, 2017). Sin embargo, para el estudio de las interacciones que se establecen entre las biomasas microbianas y los diferentes iones metálicos, se vuelve necesario el análisis de factores ambientales por su influencia en el proceso de remoción, entre los cuales destacan la temperatura, el pH, y la concentración del inóculo (biosorbente) y de los metales (Li, Peng, Yingying, Lu, \& Fan, 2016).

Si bien se han desarrollado investigaciones que evalúan condiciones bióticas y abióticas que influyen en la captura de metales (Andreoni, Finoli, Manfrin, Pelosi, \& Vecchio, 1991; Augusto-da-Costa \& Pereira, 2001; Boyanov et al., 2003), resultan aún insuficientes teniendo en cuenta las particularidades de cada biosorbente microbiano, así como de las especies metálicas. En tal sentido, para contribuir a la caracterización del proceso de remoción de metales y a la disminución de estos contaminantes en el ambiente, el presente trabajo estuvo dirigido a evaluar la remoción de cinc y cadmio por Proteus mirabilis y Bacillus subtilis, y el efecto de diferentes factores ambientales en el proceso.

\section{Materiales y métodos}




\section{Material biológico y condiciones de cultivo}

Se utilizaron dos especies bacterianas, Proteus mirabilis y Bacillus subtilis, procedentes de la colección de cultivos del Departamento de Microbiología y Virología, de la Facultad de Biología, de la Universidad de La Habana, Cuba. Los cultivos microbianos se obtuvieron en caldo nutriente, bajo condiciones de incubación de $120 \mathrm{rpm}, 30 \pm 2{ }^{\circ} \mathrm{C}$ durante 24 horas. Posteriormente se hizo la colecta de biomasa por centrifugación a 3200 rpm por 15 minutos.

\section{Remoción de cinc y cadmio por las biomasas bacterianas}

Soluciones acuosas de cinc y cadmio a una concentración de $1 \mathrm{mM}$ (milimolar) a pH 6.0, preparadas a partir de las sales de $\mathrm{CdCl}_{2} .4 \mathrm{H}_{2} \mathrm{O}$ (cloruro de cadmio tetrahidratado) y $\mathrm{ZnSO}_{4} .7 \mathrm{H}_{2} \mathrm{O}$ (sulfato de cinc heptahidratado), se pusieron en contacto, de manera individual, con las biomasas microbianas a la concentración de $2 \mathrm{~g} \cdot \mathrm{L}^{-1}$. La suspensión microorganismo-metal se mantuvo a $100 \mathrm{rpm}, 28^{\circ} \mathrm{C}$ durante 24 horas, y 
a $\mathrm{pH}$ 6.0, ajustado con $\mathrm{HCl} 0.1 \mathrm{M} \circ \mathrm{NaOH} 0.1 \mathrm{M}$, según se requirió. Después el sobrenadante se colectó por centrifugación a $3200 \mathrm{rpm}$ por 20 minutos, para el análisis de los metales residuales mediante espectrofotometría de absorción atómica Phillips PU 9100X con Ilama de aire-acetileno. En el control de la remoción de los metales se utilizaron las soluciones de los metales a la concentración establecida en cada caso, sin adición de las biomasas y manteniendo las mismas condiciones experimentales de las muestras. Para la cuantificación del cadmio, la corriente de la lámpara fue de $12 \mathrm{~mA}$ a $\lambda=228.8 \mathrm{~nm}$, y para el cinc la corriente de lámpara fue de $10 \mathrm{~mA}$ y una $\lambda=230.9 \mathrm{~nm}$. La cantidad de metal capturado por gramos de biomasa $\left(\mathrm{mg} \mathrm{g}^{-1}\right)$ se determinó según la ecuación $q=(C i-C f) V / m$ (Viera \& Volesky, 2003), donde $q$ corresponde a los $\mathrm{mg}$ de metal capturado por gramos de biomasa $\left(\mathrm{mg} . \mathrm{g}^{-1}\right)$; $\mathrm{Ci}$, la concentración inicial del metal $\left(\mathrm{mg} . \mathrm{L}^{-1}\right) ; C f$, la concentración final del metal (mg. $\left.\mathrm{L}^{-1}\right) ; m$, la masa de la biomasa en la mezcla de reacción ( $\left.\mathrm{g}\right)$, y $V$ es el volumen de la mezcla de reacción (L).

\section{Efecto de factores en la remoción de cinc y cadmio por las bacterias}

\section{Edad fisiológica del cultivo}


El crecimiento microbiano en caldo nutriente de cada bacteria se determinó a $28{ }^{\circ} \mathrm{C}$ a $100 \mathrm{rpm}$ por 24 horas. Durante este tiempo, cada dos horas se realizaron lecturas en un espectrofotómetro a una $\Lambda=640$ $\mathrm{nm}$ contra un medio sin inocular como blanco. La captura de los metales se realizó con biomasa microbiana colectada en dos estados fisiológicos correspondientes a las 6 y $24 \mathrm{~h}$ para Bacillus subtilis; en el caso de Proteus mirabilis, a las 8 y $24 \mathrm{~h}$ de crecimiento.

\section{Concentración celular}

Las biomasas húmedas, colectadas de cada cultivo bacteriano en caldo nutriente, se pusieron en contacto de tres concentraciones: 2,3 y 4 g. $\mathrm{L}^{-1}$ con los metales. Como control de este experimento se utilizó la concentración celular correspondiente a $2 \mathrm{~g} . \mathrm{L}^{-1}$.

\section{Efecto del pH}


Esta variable se ajustó y controló a diferentes valores (5.0, 6.0 y 7.0) durante el tiempo de contacto biomasa-metal (24 horas) mediante el empleo de $\mathrm{HCl} 0.1 \mathrm{M}$ o $\mathrm{NaOH} 0.1 \mathrm{M}$, según se requirió.

\section{Tiempo de contacto}

Durante 24 horas de contacto entre la biomasa y los metales se tomaron muestras a los siguientes tiempos: $\mathrm{T} 0=0 ; \mathrm{T} 1=0.5 ; \mathrm{T} 2=1 ; \mathrm{T} 3=2 ; \mathrm{T} 4$ $=4 ; \mathrm{T} 5=8 ; \mathrm{T} 6=16 ; \mathrm{T} 7=24 \mathrm{~h}$. Posteriormente, el sobrenadante con el metal residual se colectó por centrifugación a 10000 rpm durante 10 minutos y se conservó a $4{ }^{\circ} \mathrm{C}$ para posterior análisis.

\section{Pretratamiento de la biomasa}

Los cultivos bacterianos colectados por centrifugación a las 24 horas de crecimiento se inactivaron por calor seco a $60^{\circ} \mathrm{C}$ en estufa durante 12 horas. La acción del tratamiento sobre la viabilidad celular se comprobó mediante la siembra en agar nutriente de las biomasas tratadas. Posteriormente, las células inactivadas se trataron por separado con 
soluciones de $\mathrm{HCL} 0.1 \mathrm{M}$ por tres horas y de $\mathrm{KOH} 0.1 \mathrm{M}$ por dos horas. Transcurrido estos tiempos se realizaron lavados con agua destilada hasta que el $\mathrm{pH}$ alcanzó un valor de 6.0. Después de cada tratamiento, la biomasa se lavó con agua bidestilada y se secó en estufa a $60^{\circ} \mathrm{C}$ durante 12 horas para su puesta en contacto con el cinc y el cadmio. Como control del experimento se empleó biomasa microbiana no tratada (células vivas).

\section{Análisis biométricos}

Todos los experimentos se realizaron por triplicado. A los datos se les comprobó la normalidad y homogeneidad de varianza mediante las pruebas de Kolmogorov-Smirnov y Bartlett, respectivamente. Después se aplicó el test de Student para la comparación de dos medias y ANOVA de clasificación simple, y prueba de Tukey a posteriori para la comparación de más de dos medias, referidas a los niveles de remoción $(q)$ a un nivel de significación de 0.05. Para el procesamiento estadístico se empleó el programa de computación Microsoft Excel y el paquete de programas estadístico Statistica 8.0 para Windows. 
Tecnología y

Ciencias $₫$ Agua
2020, Instituto Mexicano de Tecnología del Agua

Open Access bajo la licencia CC BY-NC-SA 4.0

(https://creativecommons.org/licenses/by-nc-sa/4.0/)

\section{Resultados}

\section{Capacidad de remoción de los iones cinc y cadmio por las bacterias}

Las bacterias Proteus mirabilis y Bacillus subtilis presentaron la capacidad de remover los iones metálicos de la solución, con valores que oscilaron

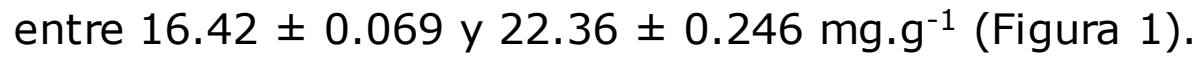

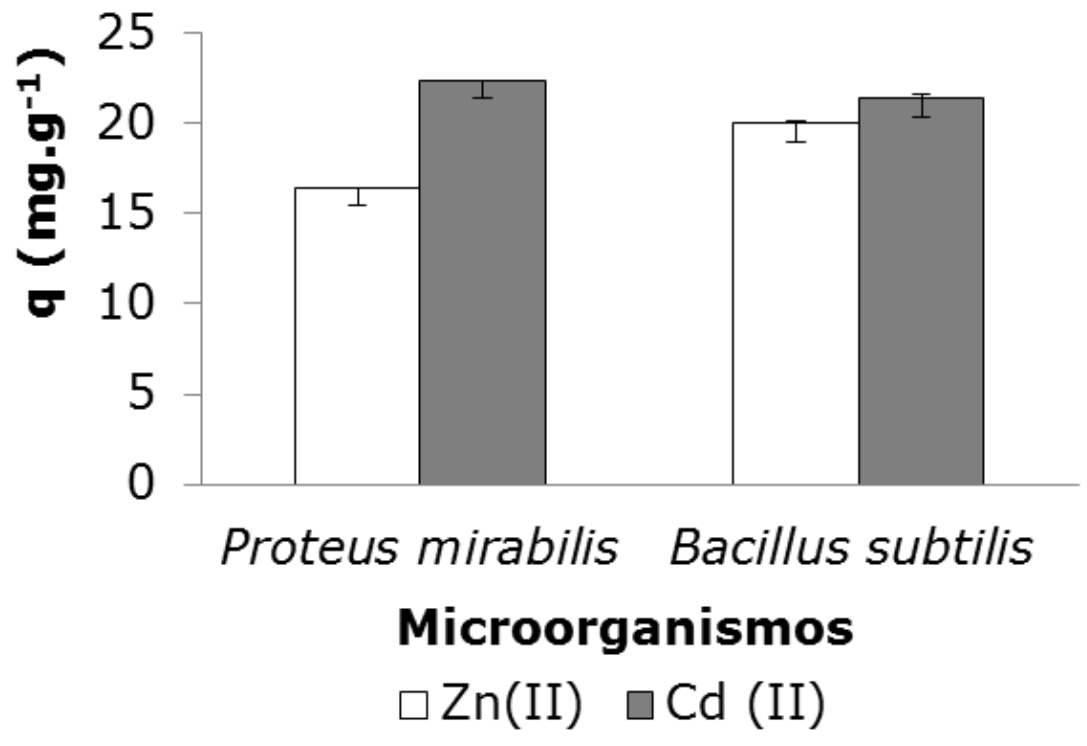

Figura 1. Remoción de Zn (II) y Cd (II) de solución acuosa por biomasas bacterianas; $28 \pm 2{ }^{\circ} \mathrm{C}$; $\mathrm{pH}$ 6.0; metal en solución: $1 \mathrm{mM}$; 
2020, Instituto Mexicano de Tecnología del Agua

Tecnología y

Ciencias $\stackrel{\Im}{\approx}$ gua
Open Access bajola licencia CC BY-NC-SA 4.0

(https://creativecommons.org/licenses/by-nc-sa/4.0/)

biomasa, 2 g.L-1; agitación 100 rpm; tiempo de contacto biomasa-metal $24 \mathrm{~h}$.

\section{Influencia de la edad fisiológica del cultivo sobre la remoción de cinc y cadmio}

Las biomasas bacterianas capturaron los iones cinc y cadmio en las dos etapas de crecimiento evaluadas, sin diferencias significativas en los niveles de captura en los dos estadios fisiológicos (Figura 2, A y B). 
Tecnología y

Ciencias $\stackrel{\unlhd}{\unlhd}$ Agua
2020, Instituto Mexicano de Tecnología del Agua

Open Access bajo la licencia CC BY-NC-SA 4.0

(https://creativecommons.org/licenses/by-nc-sa/4.0/)

Proteus mirabilis $A$
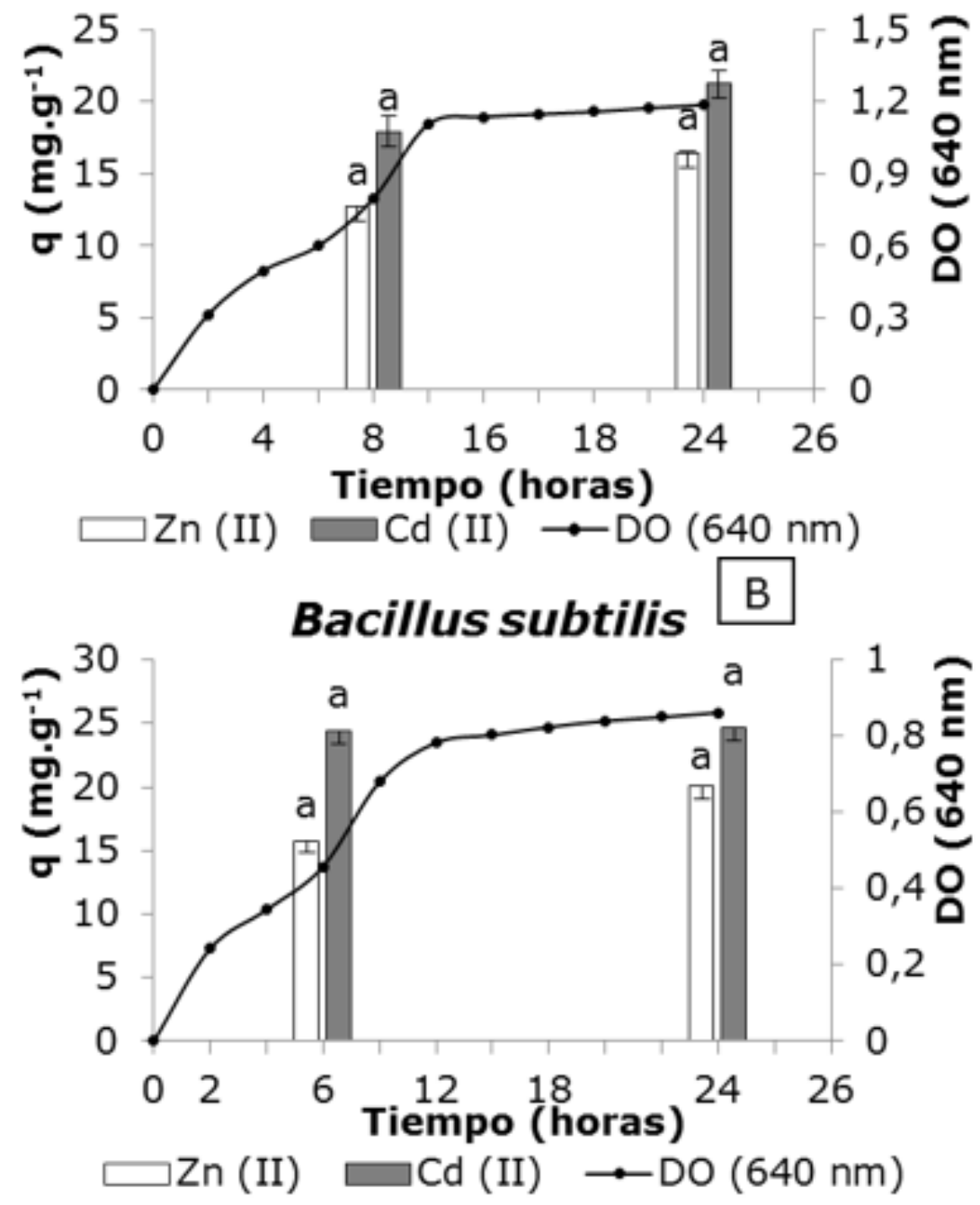

Figura 2. Influencia de la edad fisiológica del cultivo en la remoción de Zn (II) y Cd (II) de solución acuosa; $28 \pm 2{ }^{\circ} \mathrm{C}$; $\mathrm{pH}$ 6.0; metal en solución $1 \mathrm{mM}$; biomasa húmeda $2 \mathrm{~g} \cdot \mathrm{L}^{-1}$; agitación a 100 rpm, 24 h. Barras de error representan desviación estándar de tres repeticiones por estadio fisiológico. Se aplicó $t$-student para cada metal analizado. Letras diferentes sobre las barras indican diferencias significativas entre los valores de $q$ en los diferentes estadios fisiológicos para $p<0.05$. 
Tecnología y

Ciencias $\stackrel{\Xi}{\unlhd}$ Aua
2020, Instituto Mexicano de Tecnología del Agua

Open Access bajo la licencia CC BY-NC-SA 4.0

(https://creativecommons.org/licenses/by-nc-sa/4.0/)

\section{Efecto de la concentración celular}

Los datos obtenidos de captura de los iones cinc y cadmio mostraron un comportamiento diferente entre las dos bacterias. Proteus mirabilis frente a los iones de cinc no presenta diferencias significativas entre las tres concentraciones celulares ensayadas; lo mismo se observó para el cadmio a los dos concentraciones más bajas. En el caso de Bacillus subtilis, la concentración celular de $2 \mathrm{~g} \cdot \mathrm{L}^{-1}$ resultó la menor cantidad de células para alcanzar la mayor remoción de ambos metales (Figura 3).

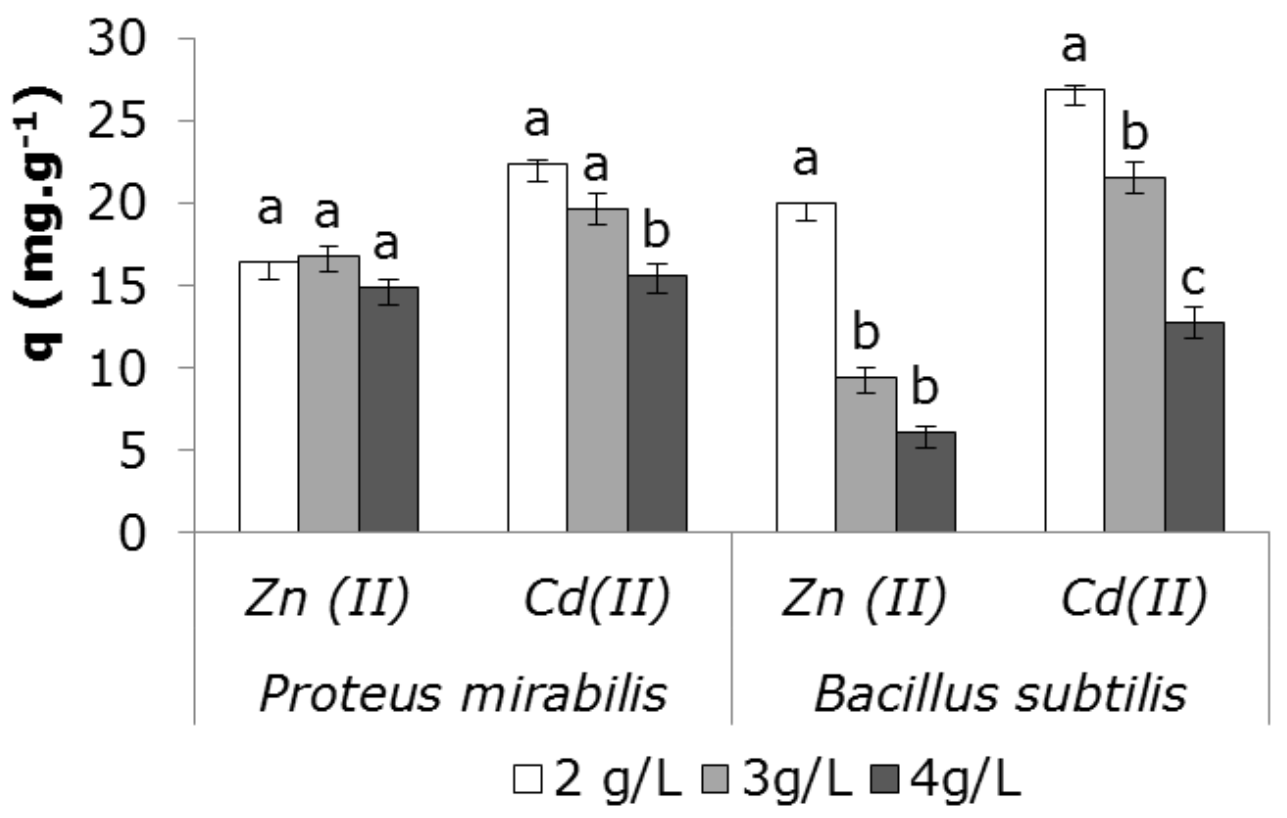


Figura 3. Efecto de la concentración celular sobre la capacidad de captura de Zn (II) y Cd (II) por las biomasas bacterianas; $28 \pm 2{ }^{\circ} \mathrm{C}$; $\mathrm{pH}$ 6.0; metal en solución 1 mM; biomasa húmeda; agitación a 100 rpm, 24 h. ( \pm ) representan desviación estándar de tres repeticiones por concentración de células. Se aplicó ANOVA de clasificación simple para cada microorganismo analizado. Letras diferentes en la tabla indican diferencias significativas entre los valores de $q$ de las diferentes concentraciones para $p<0.05$, según la prueba estadística Tukey a posteriori.

\section{Efecto del pH en la remoción de los metales}

En la Figura 4 se muestra el efecto del pH en la remoción de los metales por las biomasas bacterianas. En pH 5.0 se obtuvieron los más bajos valores de captura de ambos cationes por las bacterias; sin embargo, un efecto favorable se observa en valores neutros o cercanos a la neutralidad. 


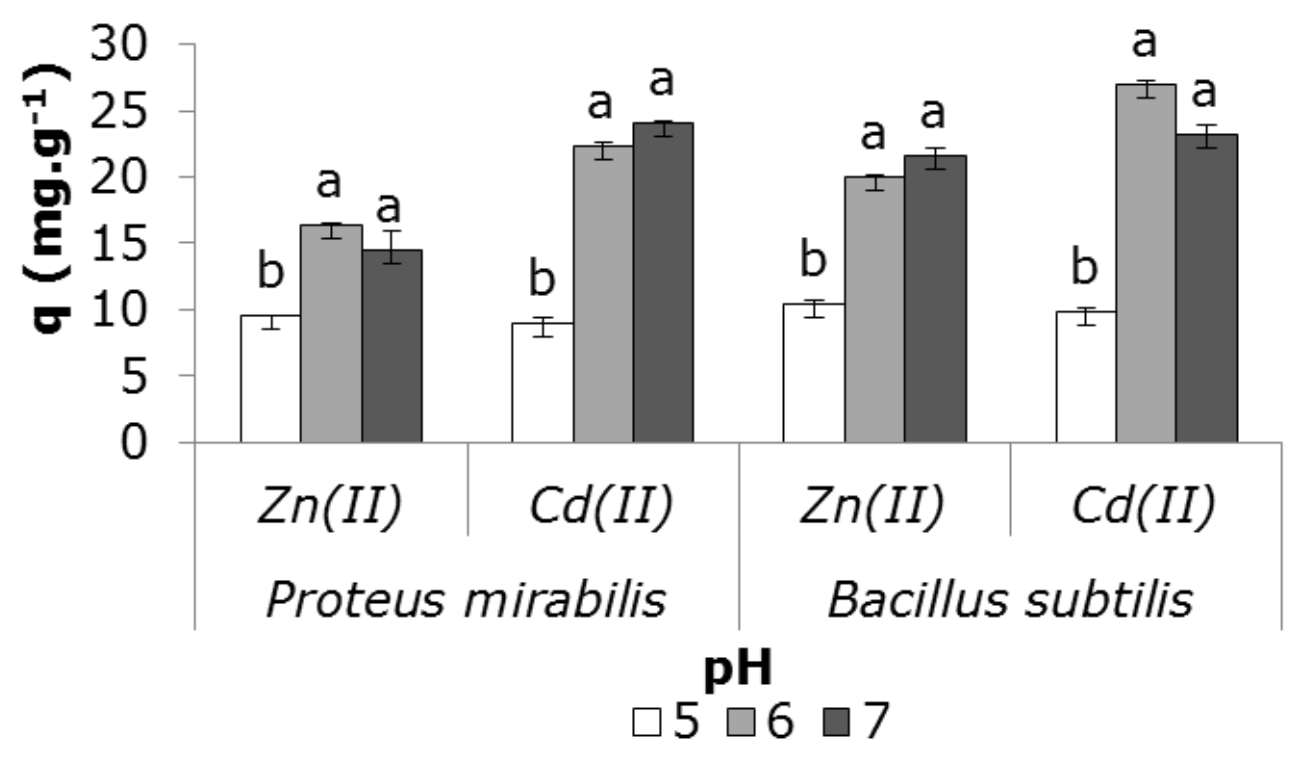

Figura 4. Efecto del pH en la remoción $\mathrm{Zn}$ (II) y Cd (II) por biomasas bacterianas; $28 \pm 2{ }^{\circ} \mathrm{C}$; metal en solución $1 \mathrm{mM}$; biomasa húmeda 2 g.L-1; agitación a 100 rpm, 24 h. Barras de error representan desviación estándar de tres repeticiones por pH. Se aplicó ANOVA de clasificación simple para cada microorganismo analizado. Letras diferentes sobre las barras indican diferencias significativas entre los valores de $q$ de los diferentes $\mathrm{pH}$ para $p<0.05$, según la prueba estadística Tukey a posteriori.

Efecto del tiempo de contacto en la remoción de los metales 
De manera general, la remoción de ambos metales es un proceso rápido en las primeras horas y después alcanza un equilibrio (Figura $5, A$ y B). Se destaca que tanto para Bacillus subtilis como para Proteus mirabilis, 6 horas son suficientes para obtener los máximos valores de captura de los iones cinc y cadmio, y el equilibrio entre su biomasa y estos metales.

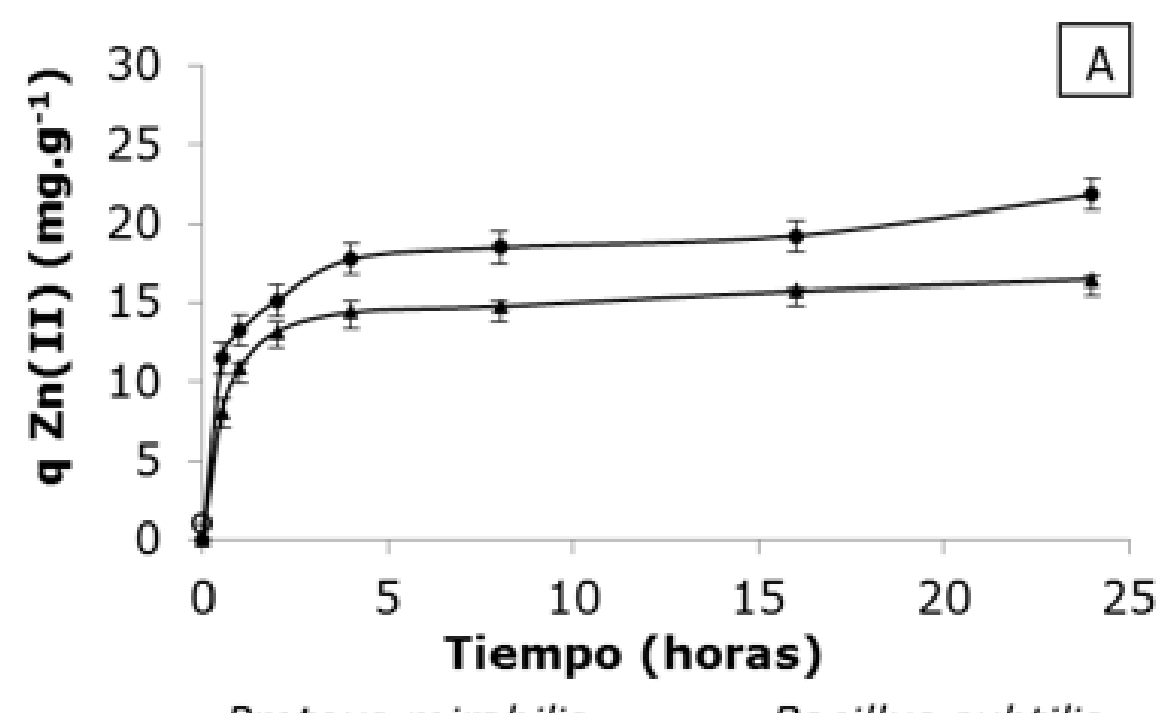

$\leftarrow$ Proteus mirabilis $\quad \rightarrow$ Bacillus subtilis

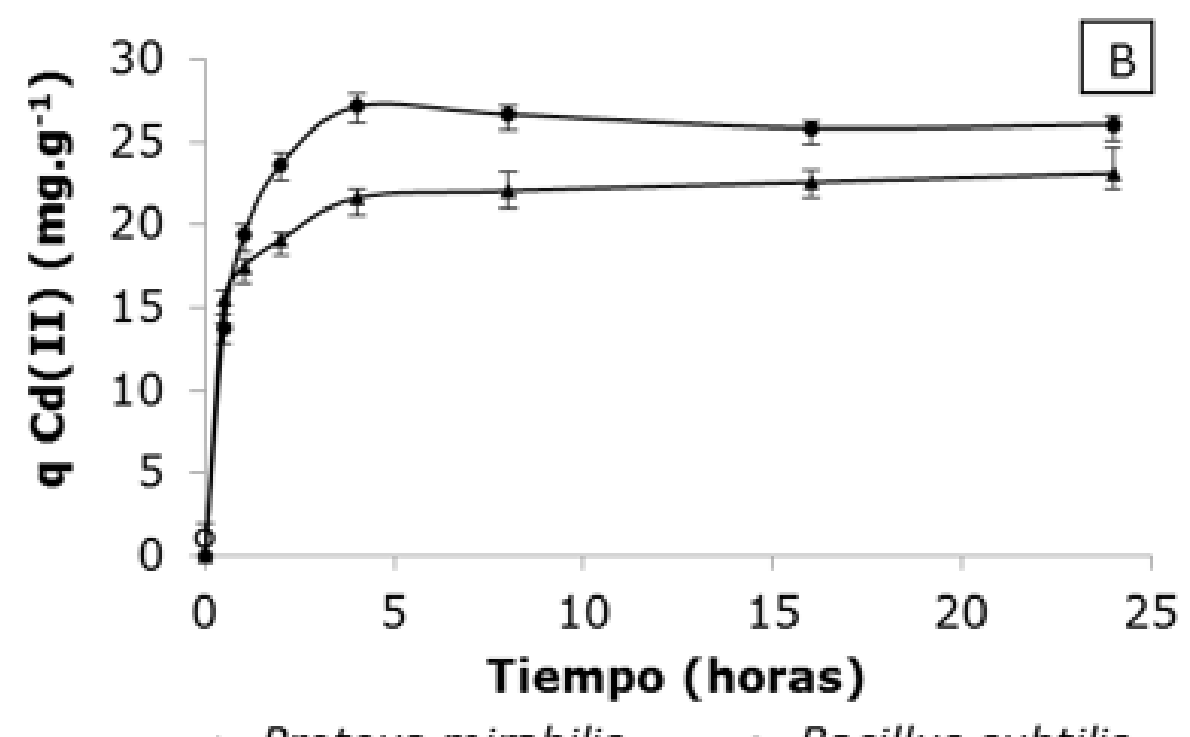

$\rightarrow$ Proteus mirabilis $\quad \rightarrow$ Bacillus subtilis 
Figura 5. Cinética de biosorción de Zn (II) (A) y Cd (II) (B) de solución por biomasas microbianas. Condiciones experimentales: $28 \pm 2{ }^{\circ} \mathrm{C} ; \mathrm{pH}$ 6.0; metal en solución 1 mM; biomasa húmeda 2 g.L-1; agitación a 100 rpm, 24 h. Barras de error representan desviación estándar de tres repeticiones por tiempo para cada microorganismo.

\section{Remoción de metales por biomasas pretratadas por métodos químicos y físicos}

De manera general se observó un incremento en los valores de captura de ambos iones por las biomasas pretratadas con respecto a las biomasas no tratadas (control) en al menos un tratamiento (Figura 6). En el caso del cinc, este efecto se evidencia sobre todo en Bacillus subtilis, donde los tres tratamientos aplicados propiciaron valores de captura superiores a los alcanzados por el control, con resultados confirmados estadísticamente. Para el cadmio se detectó una respuesta diferente, marcado por la variabilidad en el efecto de cada tratamiento sobre la remoción de este ion. En particular, se destacó en Bacillus subtilis, un efecto significativo en la captura de cadmio al tratar la biomasa con $\mathrm{KOH}$. 


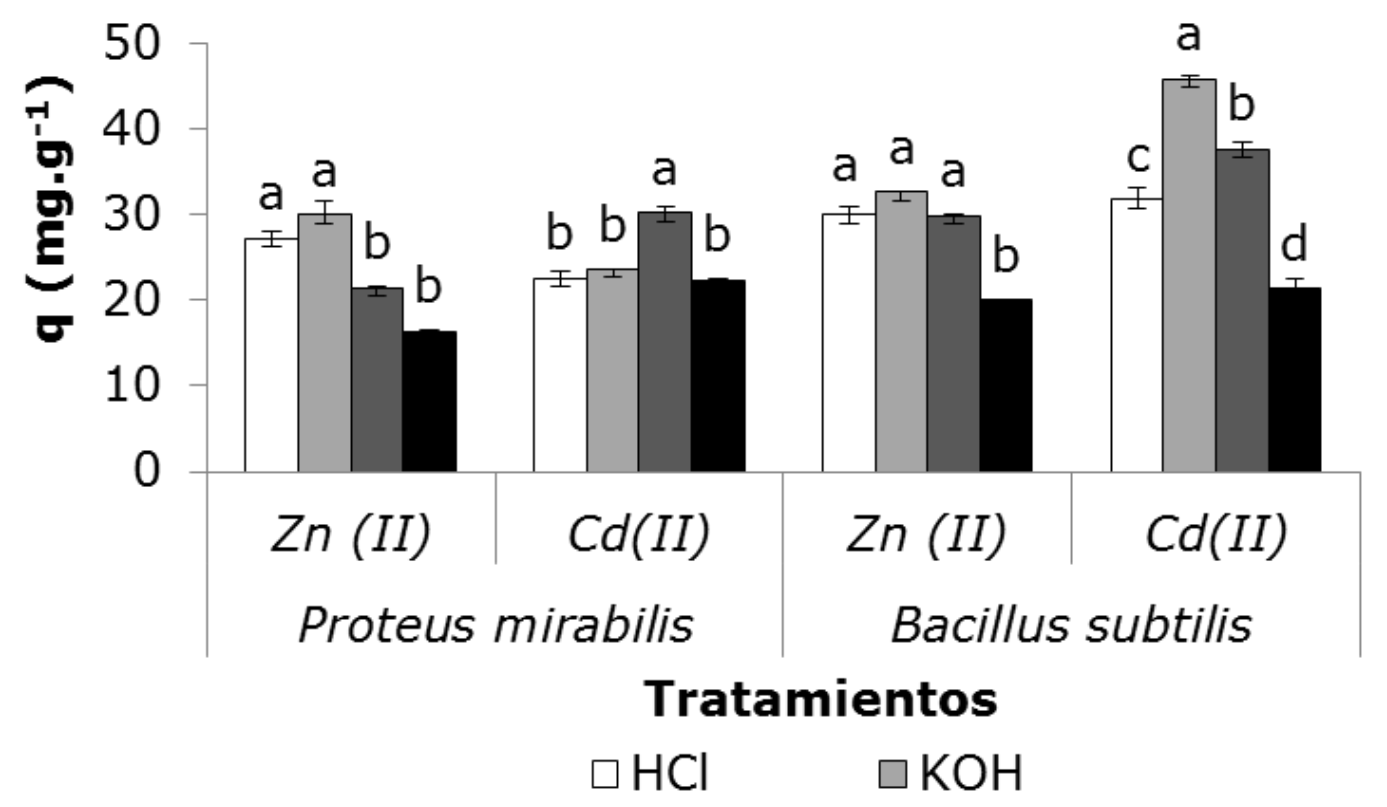

Figura 6. Remoción de Zn (II) y Cd (II) de solución acuosa por biomasas bacterianas sometidas a diferentes tratamientos; $28 \pm 2{ }^{\circ} \mathrm{C}$; metal en solución $1 \mathrm{mM}$; biomasa húmeda 2 g.L-1; agitación a 100 rpm,

$24 \mathrm{~h}$. Barras de error representan desviación estándar de tres repeticiones por tratamiento. Se aplicó ANOVA de clasificación simple para cada microorganismo analizado. Letras diferentes sobre las barras indican diferencias significativas entre los valores de $q$ de los diferentes tratamientos para $p<0.05$, según la prueba estadística Tukey a posteriori.

\section{Discusión}


Ciencias $₫$ Agua
2020, Instituto Mexicano de Tecnología del Agua

Open Access bajo la licencia CC BY-NC-SA 4.0

(https://creativecommons.org/licenses/by-nc-sa/4.0/)

Los resultados obtenidos (Figura 1) permiten inferir que la naturaleza polianiónica de la pared celular de Proteus mirabilis, caracterizada por la membrana externa de lipopolisacáridos y fosfolípidos, ofrece abundantes grupos funcionales, como carboxilos, fosfatos e hidroxilos, para la unión de cinc y cadmio (Sharma et al., 2016). Otros sitios activos en esta estructura implicados en el enlace de tales metales son aminos, hidroxilo y sulfatos (Goswami, Manikandan, Pakshirajan, \& Pugazhenthi, 2017). Disponer de estos ligandos posibilita que los metales se puedan ubicar en la región polar de la membrana o dentro de la capa de peptidoglicano, todo lo cual puede sustentar el comportamiento de esta bacteria frente a los metales ensayados. Por otro lado, en Bacillus subtilis, el contacto con los cationes puede ser por la presencia de ácidos teicoicos y teicurónico, asociados con los derivados de azúcares $\mathrm{N}$-acetil murámico y $\mathrm{N}$-acetil glucosamina, que son una fuente de grupos fosfatos y carboxilos que ofrecen carga negativa a la superficie celular. De esta manera, se favorece la unión electrostática entre la célula y los iones metálicos, y en consecuencia la captura de metales (Sharma et al., 2016). La composición química de las envolturas celulares de ambas bacterias puede constituir una vía para explicar sus capacidades de remover los iones cinc y cadmio.

Otras propiedades inherentes a los procariontes, que sustentan las interacciones que se pueden establecer entre Proteus mirabilis, Bacillus subtilis y los iones metálicos, son la elevada relación superficie-volumen (Uthra \& Kadirvelu, 2017), las características metabólicas (Kvasnová et al., 2017) y genéticas, que facilitan la adsorción y absorción de metales disueltos en solución acuosa (Chauhan et al., 2017). Al considerar la 
absorción como un posible mecanismo presente en las dos bacterias, la captura de los iones cinc y cadmio también pudiera ocurrir por acumulación intracelular. Este mecanismo mediado por sistemas de proteínas transportadoras que incorporan los metales al citoplasma ha sido referido para otras especies bacterianas en la captura de diferentes iones metálicos (Beltrán-Pineda \& Gómez-Rodríguez, 2016; Hansda, Kumar, \& Anshumali, 2016; Muñoz, Espínola, \& Ruiz, 2017).

Los niveles de captura de cinc y cadmio alcanzados por Proteus mirabilis y Bacillus subtilis cumplen con el criterio de selección informado en la literatura, donde se plantea que para competir con tecnologías convencionales en la eliminación de metales, el agente activo, en este caso el microorganismo, debe tener una capacidad de captura superior a 15 mg.g-1 (Brierley, Kelly, Seal, \& Best, 1985; Cañizares-Villanueva, 2000). Esto permite ratificar que las bacterias constituyen uno de los grupos microbianos de interés en el estudio de la remoción de metales (Ramya \& Thatheyus, 2017). Resultados similares se han informado para las especies microbianas Pseudomonas mendocina (Ps-1) (Carballo et al., 2017), Pseudomonas aeruginosa, Bacillus subtilis (Uthra \& Kadirvelu, 2017) y Klebsiella sp. 3S1 (Muñoz et al., 2017).

La remoción de cinc y cadmio por $B$. subtilis y $P$. mirabilis en las dos fases de crecimiento evaluadas (Figura 2), sugiere la participación de manera conjunta de mecanismos de acumulación intracelular y extracelular de metales. Esto se deduce por la capacidad de captar ambos metales durante las diferentes fases de crecimiento tanto en una fase de crecimiento exponencial avanzado como en fase estacionaria. La manifestación de un metabolismo activo está involucrada con un proceso de bioacumulación, mientras que la captura extracelular depende de las 
Tecnología y

Ciencias $\stackrel{\unlhd}{\unlhd}$ Agua
2020, Instituto Mexicano de Tecnología del Agua

Open Access bajo la licencia CC BY-NC-SA 4.0

(https://creativecommons.org/licenses/by-nc-sa/4.0/)

interacciones entre los cationes metálicos y los grupos activos de la superficie celular, lo cual puede ocurrir durante todo el ciclo celular. Igualmente se han explicado resultados similares obtenidos en trabajos previos (Ghaima, Mohamed, Al-Meshhdany, \& Abdulhassan, 2017).

No obstante, es importante tener en cuenta que la acumulación extracelular puede depender tanto de un metabolismo activo o no, al considerar que en las diferentes etapas fisiológicas de los cultivos microbianos es posible que ocurran alteraciones en los grupos funcionales, presentes en la pared celular, involucrados en los procesos de unión del metal a la biomasa, tal y como se ha referido en otras investigaciones (Fan, Okyay, \& Rodrigues, 2014; Ghaima et al., 2017). Los diferentes comportamientos de los microorganismos en el análisis de este factor biótico permiten plantear que la relación entre la captura de los metales y la edad del cultivo dependerá del tipo de microorganismo y sus características genéticas, así como de la especie metálica.

En relación con los resultados obtenidos en la evaluación del efecto de la concentración celular sobre la capacidad de captura en las bacterias evaluadas (Figura 3), un incremento en la concentración de células puede ocasionar una interferencia entre los sitios de unión del metal y la biomasa, lo cual puede provocar una disminución en el atrapamiento del catión. Se han informado resultados similares por parte de diferentes autores en la remoción de iones metálicos por biomasas bacterianas (Limcharoensuk et al., 2015; Choińska-Pulit, Sobolczyk-Bednarek, \& Łaba, 2018); esto puede explicar lo ocurrido en las muestras analizadas de Bacillus subtilis. 
Ciencias $₫$ Agua
2020, Instituto Mexicano de Tecnología del Agua

Open Access bajo la licencia CC BY-NC-SA 4.0

(https://creativecommons.org/licenses/by-nc-sa/4.0/)

La disminución de los valores de captura de cinc y cadmio a pH 5.0, por las dos bacterias evaluadas (Figura 4) confirman que la biosorción depende de la protonación o desprotonación de los grupos funcionales sobre la pared celular. En estas concentraciones, los iones hidronio $\left(\mathrm{H}_{3} \mathrm{O}^{+}\right)$ aumentan, y la alta movilidad iónica que presentan favorece la competencia entre éstos y el catión metálico por los grupos funcionales de unión al metal en la biomasa microbiana. El predominio que existe a este valor $\mathrm{pH}$ de cargas positivas en la superficie de la célula, que evitan la unión de las especies metálicas cargadas positivamente, se ha informado con anterioridad ( $\mathrm{Li}$ et al., 2016). Otros trabajos han referido resultados similares en la remoción de metales por diferentes biomasas bacterianas (Fan et al., 2014; Limcharoensuk et al., 2015).

Los incrementos en la captura de los iones cinc y cadmio por Proteus mirabilis y Bacillus subtilis a valores de $\mathrm{pH}$ neutro o cercanos a éste puede deberse a la presencia de menor cantidad de protones $\mathrm{H}^{+}$libres en la solución, lo que disminuye la competencia entre éstos y los iones metálicos. Además, la existencia de una menor protonación en los sitios activos de las biomasas, conlleva a un predominio de grupos cargados negativamente en la superficie celular, lo que provoca una intensificación de las fuerzas electrostáticas involucradas en el proceso de captura de los metales (Ghaima et al., 2017). Así, los ligandos en la superficie de la biomasa permiten que la reacción con los cationes sea mayor y aumente la cantidad de iones enlazados a la biomasa. Comportamientos semejantes se han detectado en la remoción de metales por diferentes biomasas microbianas (Limcharoensuk et al., 2015; Li et al., 2016; Carballo et al., 2017). 
Tecnología y

Ciencias $\stackrel{\Xi}{\unlhd}$ gua
2020, Instituto Mexicano de Tecnología del Agua

Open Access bajo la licencia CC BY-NC-SA 4.0

(https://creativecommons.org/licenses/by-nc-sa/4.0/)

Los resultados de la evaluación de la dinámica de remoción de los iones por las biomasas bacterianas (Figura 5) están en correspondencia con las características propias de estos procesos de captura de cationes metálicos por microorganismos, lo cual ocurre fundamentalmente de forma rápida en los primeros tiempos de contacto biomasa-metal. Esta particularidad reviste gran importancia para el diseño y la operacionalidad del proceso. Tal y como ocurre en el presente trabajo, otros autores señalan la existencia de dos fases en el proceso de captura de metales. No obstante, destacan que el tiempo en que se alcanza el equilibrio puede variar desde minutos hasta días, lo que dependerá del tipo de biosorbente y especie metálica, entre otros factores (Nwidi \& Agunwamba, 2015; Ling, Huang, Li, Liu, \& Cheng, 2016; Uthra \& Kadirvelu, 2017; Zhang, Hu, \& Lu, 2017).

La acción favorable del tratamiento porcalor seco aplicado a Bacillus subtilis y Proteus mirabilis, con excepción de la remoción del cinc por $P$. mirabilis (Figura 6), en relación con el control puede estar dado por la eliminación de impurezas presentes en la superficie celular y, por ende, por una mayor exposición de los grupos funcionales de unión a metales. La muerte celular de las dos bacterias, comprobada por la ausencia de crecimiento en agar nutriente después del tratamiento, condicionó un estado metabólicamente inactivo de las células tratadas, en las que están ausentes los sistemas de transporte que permitirían la bioacumulación del metal y, por tanto, es posible una mayor capacidad de biosorción en la superficie celular. En el caso de las biomasas inactivadas, tratadas con $\mathrm{HCl}$ y $\mathrm{KOH}$, presentaron variaciones en sus propiedades de enlazar los metales. Este resultado es coincidente con los informados por otros autores (Hansda et al., 2016). Los agentes químicos aplicados en el 
presente trabajo pueden potenciar las interacciones electrostáticas, pues facilitan la formación de condiciones óptimas para el intercambio iónico e incrementan los sitios de unión para los cationes metálicos. De esta manera se han sustentados resultados previos (Zeraatkar, Ahmadzadeh, Talebi, \& Moheimani, 2016).

Está bien documentado que en el proceso de biosorción está involucrada sobre todo la pared celular y que su modificación puede potenciar la captura de los iones metálicos (Barange, Srivastava, Srivastava, \& Palsania, 2014; Hansda et al., 2016). Otros autores refieren que la efectividad de los tratamientos va a depender, entre otros factores, de la especie metálica y del microorganismo (Mota et al., 2016), así como del mecanismo o submecanismo que gobierna la captura de los iones por las biomasas microbianas (Kiran, Rani, \& Kaushik, 2016). No obstante, han sido bien respaldados en la literatura como alternativa para incrementar la remoción de metales (Shoaib, Aslam, \& Aslam, 2013).

\section{Conclusiones}

El empleo de microorganismos para la biosorción de metales representa una alternativa en la búsqueda de una solución económica y amigable con el medio ambiente. Los valores de captura de cinc y cadmio por las biomasas microbianas evidenciaron las potencialidades de Bacillus subtilis 
y Proteus mirabilis para la eliminación de estos metales presentes en soluciones acuosas. Sin embargo, se demostró que las potencialidades naturales se pueden favorecer mediante la caracterización de los diferentes factores asociados con la remoción de iones metálicos, y la modificación de las biomasas con los tratamientos físicos y químicos. Entre los factores que más incidieron en el mejoramiento de los niveles de remoción están el tiempo de contacto biomasa-metal, el pH y los tratamientos aplicados. Las células inactivadas constituyen una condición favorable para el uso de ambas bacterias sin riesgo ambiental y en particular para la salud. Otro dato notable aportado es la demostración de que 6 horas son suficientes para lograr la máxima captura del cinc y del cadmio, lo que reviste gran relevancia en el camino para hacer económicamente más viable la aplicación de estas biomasas bacterianas en procesos biotecnológicos.

\section{Referencias}

Andreoni, V., Finoli, C., Manfrin, P., Pelosi, M., \& Vecchio, A. (1991).

Studies on the accumulation of cadmium by a strain of Proteus mirabilis. FEMS Microbiology Ecology, 85, 183-192.

Augusto-da-Costa, A. C., \& Pereira, F. (2001). Bioaccumulation of copper, zinc, cadmium and lead by Bacillus sp., Bacillus cereus, Bacillus sphaericus and Bacillus subtilis. Brazilian Journal of Microbiology, $32,1-5$.

Barange, M., Srivastava, A., Srivastava, J. K., \& Palsania, J. (2014). Biosorption of heavy metals from wastewater by using microalgae. 
Tecnología y

Ciencias $\stackrel{\unlhd}{\unlhd}$ Agua
2020, Instituto Mexicano de Tecnología del Agua

Open Access bajo la licencia CC BY-NC-SA 4.0

(https://creativecommons.org/licenses/by-nc-sa/4.0/)

International Journal of Chemical and Physical Sciences, 3(6), 6781.

Beltrán-Pineda, M. E. \& \& Gómez-Rodríguez, A. M. (2016). Biorremediación de metales pesados cadmio (Cd), cromo $(\mathrm{Cr})$ y mercurio $(\mathrm{Hg})$ mecanismos bioquímicos e ingeniería genética: una revisión. Revista Facultad de Ciencias Básicas, 12(2): 172-197.

Boyanov, M. I., Kelly, S. D., Kemner, K. M., Bunker, B. A., Fein, J. B., \& Fowle, D. A. (2003). Adsorption of cadmium to Bacillus subtilis bacterial cell walls: A pH-dependent X-ray absorption fine structure spectroscopy study. Geochimica et Cosmochimica Acta, 67, 18, 3299-3311.

Brierley, C. L., Kelly, D. P., Seal, K. J., \& Best, D. J. (1985). Materials and Biotechnology. In: Higgins I. J., Best D. J., \& J. Jones (eds.). Biotechnology. Principles and Applications, $2^{\text {nd }}$ ed. (pp. 163-212). Oxford, UK: Blackwell Science Ltd.

Cañizares-Villanueva, R. (2000). Biosorción de metales pesados mediante el uso de biomasa microbiana. Revista Latinoamericana de Microbiología, 42, 131-143.

Carballo, M. E., Martínez, A., Salgado-Bernal, I., Pérez, L., Cruz, M., Liva, M. B., Allende, S., Rodríguez, M. M., \& Garza, Y. (2017). Standardization of variables involved in cadmium and zinc microbial removal from aqueous solutions. Biotecnología Aplicada, 33, 12211225.

Chauhan, M., Solanki, M., \& Nehra, K. (2017). Putative mechanism of cadmium bioremediation employed by resistant bacteria. Jordan Journal of Biological Sciences, 10(2), 101-107. 
Tecnología y

Ciencias $₫$ Agua
2020, Instituto Mexicano de Tecnología del Agua

Open Access bajo la licencia CC BY-NC-SA 4.0

(https://creativecommons.org/licenses/by-nc-sa/4.0/)

Choińska-Pulit, A., Sobolczyk-Bednarek, J., \& Łaba, W. (2018). Optimization of copper, lead and cadmium biosorption onto newly isolated bacterium using a Box-Behnken design. Ecotoxicology and Environmental Safety, 149, 275-283.

Chowdhury, S., Jafar, M. A., Al-Atta, O., \& Husain, T. (2016). Heavy metals in drinking water: Occurrences, implications and future needs in developing countries. Science of the Total Environment, 569-570, 476-488.

Essa, A. M. M., Al-Abboud, M. A., \& Khatib, S. I. (2017). Metal transformation as a strategy for bacterial detoxification of heavy metals. Journal of Basic Microbiology, DOI: 10.1002/jobm.201700143.

Fan, J., Okyay, T. O., \& Rodrigues, D. F. (2014). The synergism of temperature, $\mathrm{pH}$ and growth phases on heavy metal biosorption by two environmental isolates. Journal of Hazardous Materials, 279, 236-243.

Ghaima, K. K., Mohamed, A. I., Al-Meshhdany, W. Y., \& Abdulhassan, A. A. (2017). Resistance and bioadsorption of cadmium by Pseudomonas aeruginosa isolated from agricultural soil. International Journal of Applied Environmental Sciences, 12(9), 1649-1660.

Goswami, L., Manikandan, N. A., Pakshirajan, K., \& Pugazhenthi, G. (2017). Simultaneous heavy metal removal and anthracene biodegradation by the oleaginous bacteria Rhodococcus opacus. 3 Biotech, 7(37), 2-9. 
Hansda, A., Kumar, V., \& Anshumali. (2016). A comparative review towards potential of microbial cells for heavy metal removal with emphasis on biosorption and bioaccumulation. World Journal of Microbiology Biotechnology, 32(170), 1-14.

Irawati, W., Riak, S., Sopiah, N., \& Sulistia, S. (2017). Heavy metal tolerance in indigenous bacteria isolated from the industrial sewage in Kemisan River, Tangerang, Banten, Indonesia. Biodiversitas, $18(4), 1481-1486$.

Kiran, B., Rani, N., \& Kaushik, A. (2016). FTIR spectroscopy and scanning electron microscopic analysis of pretreated biosorbent to observe the effect on $\mathrm{Cr}$ (VI) remediation. International Journal of Phytoremediation, DOI: 10.1080/15226514.2016.1183577.

Kjellstrom, T., \& Nordberg, G. F. (1985). Kinetic model of cadmium metabolism. In: Fridberg, L., Elinder, C. G., Kellstrom, T., \& Nordberg, G. F. (eds.). Vol I. Cadmium and health, a toxicological and epidemiological appraisal (pp. 179-197), Boca Raton, USA: CRC Press.

Kvasnová, S., Hamarováb, L., \& Pristašc, P. (2017). Zinc bioaccumulation by microbial consortium isolated from nickel smelter sludge disposal site. Nova Biotechnologica et Chimica, 16(1), 48-53.

Li, X., Peng, W., Yingying, J., Lu, L., \& Fan, W. (2016). Removal of cadmium and zinc from contaminated wastewater using Rhodobacter sphaeroides. Water Science and Technology, DOI: 10.2166/wst.2016.608.

Limcharoensuk, T., Sooksawat, N., Sumarnrote, A., Awutpet, T., Kruatrachue, M., Pokethitiyook, P., \& Auesukaree, C. (2015). 
Tecnología y

Ciencias $\stackrel{\unlhd}{\unlhd}$ Agua
2020, Instituto Mexicano de Tecnología del Agua

Open Access bajo la licencia CC BY-NC-SA 4.0

(https://creativecommons.org/licenses/by-nc-sa/4.0/)

Bioaccumulation and biosorption of $\mathrm{Cd}^{2+}$ and $\mathrm{Zn}^{2+}$ by bacteria isolated from zinc mine in Thailand. Ecotoxicology and Environmental Safety, 122, 322-330. Recuperado de http://dx.doi.org/10.1016/j.ecoenv.2015.08.013.

Ling, W., Huang, S., Li, X., Liu, M., \& Cheng, Y. (2016). Bio-remediation of acephate- $\mathrm{Pb}$ (II) compound contaminants by Bacillus subtilis FZUL-33. Journal of Environmental Sciences, 45, 94-99.

Mehta, A., \& Kumar, S. (2017). Heavy metals as a threat to aquatic environments. International Journal of Current Microbiology and Applied Sciences, 6(6), 386-389.

Mota, R., Rossi, F., Andrenelli, L., Bernardes, S., De Philippis, R., \& Tamagnini, P. (2016). Released polysaccharides (RPS) from Cyanothece sp. CCY 0110 as biosorbent for heavy metals bioremediation: Interactions between metals and RPS binding sites. Applied Microbiology and Biotechnology, DOI: 10.1007/s00253016-7602-9.

Muñoz, A. J., Espínola, F., \& Ruiz, E. (2017). Biosorption of Ag (I) from aqueous solutions by Klebsiella sp. 3S1. Journal of Hazardous Materials, 329,166-177.

Nwidi, I. C., \& Agunwamba, J. C. (2015). Selection of biosorbents for biosorption of three heavy metals in a flow metals in a flow-batch reactor using removal efficiency as parameter. Nigerian Journal of Technology, 34(2), 406-413.

Nour-Abdel-Ghani, T., \& Ghadir-El-Chaghaby, A. (2014). Biosorption for metal ions removal from aqueous solutions: a review of recent 
studies. International Journal of Latest Research in Science and Technology, 3(1), 24-42.

Ramya, D., \& Thatheyus, A. J. (2017). Microscopic investigations on the biosorption of heavy metals by bacterial cells: A review. Science International, 6(1), 11-17.

Salgado-Bernal I., Pérez, J. E., Carballo, M. E., Martínez, A., \& Cruz, M. (2015). Aplicación de rizobacterias en la biorremediación del cromo hexavalente presente en aguas residuales. Revista Cubana de Ciencias Biológicas, 4(2), 20-34.

Sharma, S., Rana, S., Thakkar, A., Baldi, A., Murthy, R. S. R., \& Sharma, R. K. (2016). Physical, chemical and phytoremediation technique for removal of heavy metals. Journal of Heavy Metal Toxicity and Diseases, 1(2), 1-15.

Shoaib, A., Aslam, N., \& Aslam, N. (2013). Trichoderma harzianum: Adsorption, desorption, isotherm and FIIR studies. Journal of Animal and Plant Sciences, 23(5), 1460-1465.

Uthra, K., \& Kadirvelu, K. (2017). Biosorption of nickel using mixed cultures of Pseudomonas aeruginosa and Bacillus subtilis. Defence Life Science Journal, 2(4), 442-447.

Viera, R., \& Volesky, B. (2003). Biosorption: A solution to pollution? International Microbiology, 3, 17-24.

Volesky, B. (1994). Advances in biosorption of metals: Selection of biomass types. Microbiology Reviews, 14, 291-302. 
2020, Instituto Mexicano de Tecnología del Agua

Tecnología y

Open Access bajo la licencia CC BY-NC-SA 4.0

(https://creativecommons.org/licenses/by-nc-sa/4.0/)

Zeraatkar, A. K., Ahmadzadeh, H., Talebi, A. F., \& Moheimani, N. R. (2016). Potential use of algae for heavy metal bioremediation, a critical review. Journal of Environmental Management, 30, 1-15.

Zhang, H., Hu, X., \& Lu, H. (2017). Ni (II) and $\mathrm{Cu}$ (II) removal from aqueous solution by a heavy metal-resistance bacterium: Kinetic, isotherm and mechanism studies. Water Science and Technology, DOI: $10.2166 /$ wst.2017.275 